\title{
A STUDY OF THE CIRCULATION IN OBESITY ${ }^{1}$
}

By S. H. PRODGER AND H. DENNIG

(From the University Medical Clinic, Heidelberg, Germany)

(Received for publication March 10, 1932)

The status of the circulatory system in obesity has been the subject of considerable interest, study, and conjecture for many years. Laennec (1) mentioned the "fatty heart" as an anatomic condition, while Stokes (2) thought he could recognize it clinically. In more recent years chief interest has centered on the pathologic physiology of the condition and the clinical conception of the fatty heart as such has, for all practical purposes, passed into discard. It is recognized that symptoms which may be taken as evidence of cardiac insufficiency may manifest themselves in obesity where the pathological changes found in the circulatory system seem hardly commensurate with these symptoms. Many have considered the primary disturbance in these cases to be in the heart, and Hirsch (3), who showed that the muscle mass of the heart is relatively small for the weight of the obese patient, looked upon this disproportion as an important factor in the relative inefficiency of the heart in obesity; Romberg (4) also holds this view. The mechanical disturbances produced by the thick epicardial fat layer as well as by the height of the diaphragm with subsequent transverse displacement of the heart are also considered as significant hindrances to satisfactory cardiac function. At any rate, the condition of the circulatory system is a subject of prime importance in obesity and in most cases the prognosis of the disease is chiefly dependent upon it. Following the monograph of Eppinger, Kisch, and Schwarz (5), in which such an intimate inter-relationship was suggested between circulatory and metabolic disturbances, an attempt was made to find in the metabolic abnormalities of obesity factors which might explain its circulatory maladjustments. As Groscurth (6) notes, circulatory diseases are responsible sooner or later for disturbances in metabolism, and vice versa.

In the present study an attempt was made to analyze through a many-sided study of the circulatory system the factors responsible for the picture of so-called relative cardiac insufficiency in obesity. Are the symptoms due purely to mechanical disturbances, are they due to some intrinsic weakness of the heart, or are they due to metabolic abnormalities?

${ }^{1}$ Aided by a grant from the Ella Sachs Plotz Fund. 
It seemed that a satisfactory way to study the circulation in obese patients would be to observe the effect of measured exercise under carefully defined conditions on various phases of the circulation, and to compare these results with the results obtained under similar conditions in a group of normal people.

Three obese patients were compared with three normal persons. The results in the three cases of obesity were so consistent that it was thought much more would not be gained by studying a larger group of similar cases. A fourth normal person was studied who was of such size that his normal weight approximated that of one of the obese patients. The obese patients exhibited beyond simple obesity no abnormalities which could in any way be associated with the circulatory system.

The cases were studied in the sitting and standing resting positions, during and after exercise. The exercise consisted of walking on a treadmill and was of such a character as to be most typical of the exercise which a fat person would be likely to perform in the routine of his daily life. It was also selected as a suitable form of exercise because so many muscles of the body were put to use. The exercise was in no way severe; so that the problem of exhaustion was excluded.

We arbitrarily selected for study the following phases connected directly or indirectly with the circulatory system of the blood: Vital capacity, respiratory minute volume, respiratory rate, oxygen consumption, respiratory quotient, arteriovenous oxygen difference, cardiac output, pulse rate, stroke volume, blood pressure, lactic acid and other blood changes.

\section{METHOD}

The experiments were all done in the forenoon after at least twelve hours fasting and after one-half hour of rest in a semi-reclining position in a comfortable chair. The experiments on the obese patients were performed before reduction diet was fully established. On the day before experiments were to be performed, a general mixed diet of approximately 2500 calories was given. No attempt was made to analyze the work performed in kilogram meters, but the amount of exercise was regulated by fixing the treadmill at a certain number of revolutions per minute so that each patient walked exactly the same distance in seven minutes. Seven minutes was considered sufficient time to allow the oxygen consumption to reach a "steady state" (7 and 8). All the individuals studied performed the exercise at least four times before the experiments were carried out, and the experiments were in every case repeated. After this training, a gradual significant decrease in oxygen consumption was not observed when the experiments were repeated. The short period of training (performing the walking exercise on 4 successive days before the experiments were begun), which we instituted, was apparently sufficient to control to a satisfactory degree the training factor in the mild exercise which we studied.

The experiments were carried out as follows: The patient, seated in a comfortable chair on the treadmill, breathed into a 125 liter spirometer for 10 minutes. The expired air collected in these 10 minutes was analyzed to estimate the basal values for oxygen consumption and $\mathrm{CO}_{2}$ output. The chair 
was then removed and as soon as the patient was comfortably erect the treadmill was set into motion at a speed of 66.7 meters per minute. The change from sitting to standing position was made without detaching the mouthpiece. The expired air during the first two minutes of the exercise was not collected, but the 3 rd and 4 th, 5 th and 6 th, and 7 th minute samples were collected separately by switching the expired air alternately from one spirometer to another. At the end of the 7 minutes the treadmill was stopped, the chair was replaced, and the patient sat comfortably for 40 minutes, during which time all the expired air was collected at intervals of 5 and 10 minutes. All the expired air samples were analyzed in a Haldane apparatus for $\mathrm{O}_{2}$ and $\mathrm{CO}_{2}$. (It was found that the increased oxygen consumption in rest resulting from the previous exercise actually did not extend beyond 20 minutes into the resting period.) The expired air during the first minute following exercise was not obtained so that the oxygen "debt" figures in all cases do not include this minute. During this minute the blood samples were collected.

The output of blood from the heart was determined on another day. The value for the cardiac output was obtained in standing at rest, during exercise (at the end of 7 th minute), and 4 minutes after the walking. In the measurement of the cardiac output during exercise a three-way valve was used so that it was not necessary to change the mouthpiece in switching from the spirometer to the gas mixture in the balloon. At rest the 2 acetylene samples were collected at the 15th and 20th seconds, in exercise at the 12th and 16th seconds. The expired air and the acetylene mixtures were analyzed in a Haldane apparatus to which had been added a third absorber for acetylene. The values for cardiac output were obtained using the thoroughly reliable acetylene method, as described by Marshall and Grollman (9) and by Grollman (10).

Samples of venous blood were collected at rest and immediately following exercise. In two cases arterial blood was collected before and after exercise. The changes in $\mathrm{pH}, \mathrm{CO}_{2}$ tension $\left(\mathrm{pCO}_{2}\right)$, and $\mathrm{CO}_{2}$ content of the arterial samples were noted. The $\mathrm{CO}_{2}$ content of the arterial blood was measured according to the method of Van Slyke and Stadie (11), the $\mathrm{pH}$ according to Hastings and Sendroy (12), and the $\mathrm{pCO}_{2}$ according to the formula as given by Austin, et al. (13). Lactic acid values were measured in the venous blood by the method of Hirsch-Kaufmann (14), as modified by Lehnartz (15).

By means of the described experiments we observed how the circulatory response in an obese person differed from that in a normal person when each walked 467 meters in 7 minutes at a steady pace. This difference in response could, of course, be considered as due entirely to the extra weight of the obese person, and the disturbances which this extra weight produced. As mentioned above, we had available for study one subject of normal development, rather muscular, and of such size that his weight, which was normal for his size, was exactly the same as the weight of one of the obese subjects (case 3 ). These two were also of approximately the same age (29 and 31); one was a male and the other a female. In these two patients we may assume that the quantity of work performed by each in the walking test was approximately the same. Any marked differences in the circulatory and metabolic responses might be considered as due to superfluous fat.

The essential facts concerning the cases of obesity studied are briefly given.

\section{PROTOCOLS}

Case 1. F. S., a male, was 48 years of age, weighed $104 \mathrm{kgm}$., and was 166 $\mathrm{cm}$. in height. His chief complaint was his extra weight. The patient had occasional palpitation when walking very fast. He suffered from slight edema 
about the ankles in the evenings when he had been on his feet a great deal during the day. He complained of moderate dyspnea on exertion, especially when he attempted to blow his horn while marching with a band. He had also noticed increased dyspnea which was definitely related to increasing weight. His mother, two brothers, and three sisters were "very fat." He had been moderately stout (80-85 kilos) for some fifteen years until five years ago when he began gaining considerable weight. He had gained about 25 kilograms in the past five years. This gain was associated with a change in living conditions, at which time there was a definite increase in food consumption, particularly in foods of high fat content.

The fat was symmetrically distributed. There was nothing to suggest a so-called "endogenous obesity." The heart was not enlarged to percussion. There were no murmurs. The second aortic tone was equal in intensity to the second pulmonic; the rhythm was regular; the blood pressure was systolic 130 , diastolic 85 . The pulse rate over a period of a few weeks was usually 80 . There was no edema, the liver was not enlarged, the lungs were clear. Roentgenogram showed a transversely placed heart with a high diaphragm, which was freely movable. The heart was of normal size. The basal metabolism was normal, and the Wasserman reaction was negative.

Case 2. K. B. was a male, aged 28 years, weighing $96.5 \mathrm{kgm}$. His height was $163 \mathrm{~cm}$. He complained of obesity, palpitation, nervousness, and dyspnea on exertion. He feared heart trouble. His mother was obese. The patient had been only slightly above average weight since childhood, and the rapid increase in weight had come only in the past six months, during which time he thought he had gained some 10 to 15 kilograms. He had always had an extremely good appetite but gave no satisfactory history as to food intake in connection with the recent gain in weight. The patient was very nervous, easily upset, and frequently trembled all over.

In this case too the fat was symmetrically distributed and there were no signs suggestive of endocrine disturbance. The patient had masculine trichosis. There was no disturbance in water metabolism. The heart exhibited no abnormalities on physical examination. The blood pressure was systolic 140, diastolic 95. There was no edema. The x-ray examination showed a freely movable, high diaphragm, and a heart of normal size which was transversely placed. Electrocardiogram showed only a left axis deviation, of the type considered as being due to position change (16). The basal metabolism was normal. The Wassermann test, blood-film pictures, and urinalysis were negative.

Case 3. E. W. was a female, 31 years of age, who weighed $88 \mathrm{kgm}$., and was $158 \mathrm{~cm}$. in height. She complained of headaches, palpitation, dyspnea on exertion, general nervousness, weakness, and easy fatiguability. Her mother weighed over 100 kilograms. At 14 the patient weighed 46 kilograms, but at 21 she began to grow stout. Her weight gradually increased. In the past 4 years, since her marriage, there had been a more rapid increase in weight, especially in the face and body. Her forearms and legs were always free from excessive fat. The patient said that her appetite was not particularly good, but that she took a large amount of fluids, especially beer. Palpitation, dyspnea, and fatiguability had gradually increased with increase in weight. The general nervousness, irritability, and headaches seemed definitely associated with a sexual neurosis. No edema was found. Menstrual periods were regular but always slight. The patient had never been pregnant.

The forearms, hands, legs, and feet were relatively free from fat. She had a fat face, thick fat neck, very large breasts and abdomen. The skin was not unusual. The fundus and visual fields were normal. The thyroid was not 


\begin{tabular}{|c|c|c|c|c|c|c|c|c|}
\hline oppropp noqures & 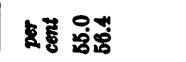 & & & 모용 & & & & \\
\hline $\mathbf{H}^{\mathrm{d}}$ & 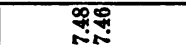 & & & 군? & & & & \\
\hline p!os opquet & ह్ & 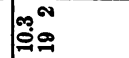 & & $\div \infty$ & ن요 & & \%ำ & $\infty 0^{\circ}$ \\
\hline $\begin{array}{l}\text { ansespd } \\
\text { poorg }\end{array}$ & 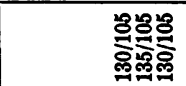 & 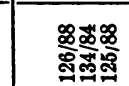 & 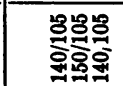 & 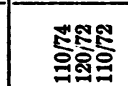 & 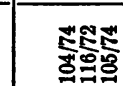 & 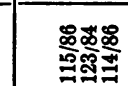 & 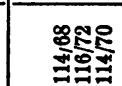 & 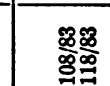 \\
\hline धঞगत & ఐ ஐన్షియ & 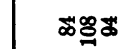 & க৪ః & 요 & నిகం & జळ్తి & న゙ळกี & สะ \\
\hline 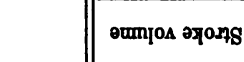 & 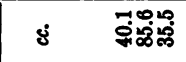 & 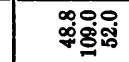 & क⿻ & 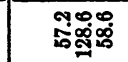 & 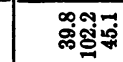 & 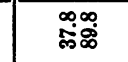 & ิํㅇ웝ํำ & $\stackrel{\infty}{\Rightarrow}$ \\
\hline әштпן & 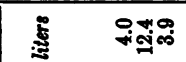 & 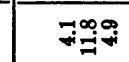 & ํㅗ웜 & 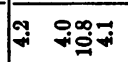 & 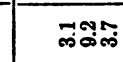 & 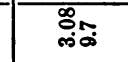 & 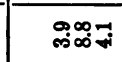 & $\Xi$ \\
\hline 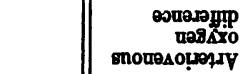 & 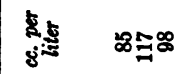 & トฆ尺 & జు్ㅀ & 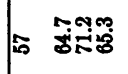 & ఉळळ & :\% & 휴유 & 8 \\
\hline 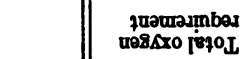 & \& \% & 옹 & 䒜 & \&్థ & ํㅐㅇ & 윰 & 品 & శ్ \\
\hline 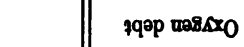 & \& & ষ্ & \%ి & ళ్రి & 욤 & สิ & 8 & 윢 \\
\hline 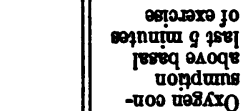 & \& & 윰 & 윰 & ళ్สి & ఫ్సి & : & 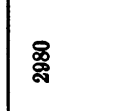 & \%్ \\
\hline 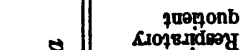 & 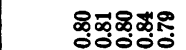 & 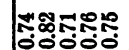 & మొమళమ & జద్మం:ం & 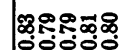 & 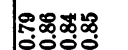 & 2R: & 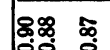 \\
\hline 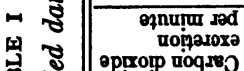 & 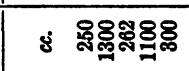 & 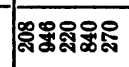 & 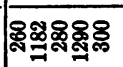 & 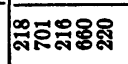 & 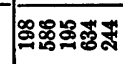 & 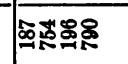 & 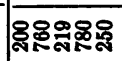 & స్సీ용 尺 \\
\hline $\begin{array}{l}\text { annuịu Lad } \\
\text { uo!̣dumsuos }\end{array}$ & 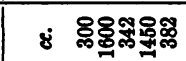 & 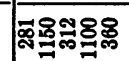 & 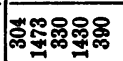 & 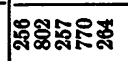 & 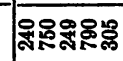 & 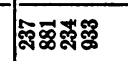 & 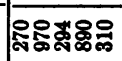 & 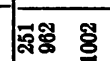 \\
\hline 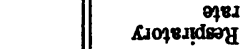 & ㅍ్요요 & תפ & జన్ణాల్లా & 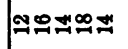 & 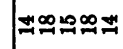 & $=\infty$ & 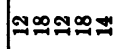 & $\approx \infty$ \\
\hline 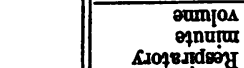 & 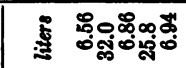 & \%ం: & : Fim & 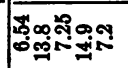 & 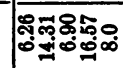 & 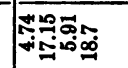 & 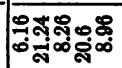 & 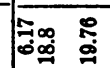 \\
\hline 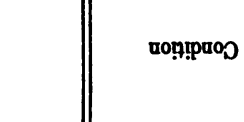 & 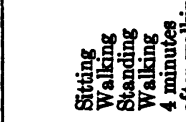 & ) & 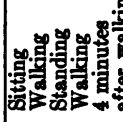 & 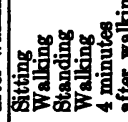 & 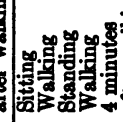 & 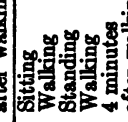 & 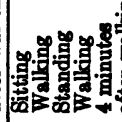 & 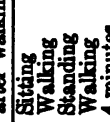 \\
\hline oqea & 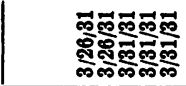 & 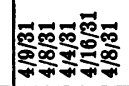 & 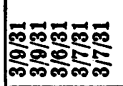 & 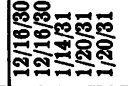 & 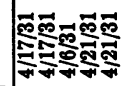 & 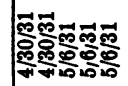 & 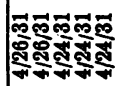 & 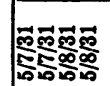 \\
\hline 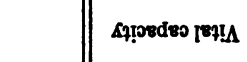 & 옳 & శ్ & \&్ & \&్ర & ళ্ক & \% & 8 & 8 \\
\hline 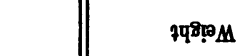 & ह & $\infty$ & $\ddot{\circ}$ & $\%$ & $R$ & $\infty$ & $\infty$ & $R$ \\
\hline 2पจุตम & E & $\$$ & $\dddot{\pi}$ & ? & 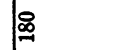 & $\underline{E}$ & 必 & 요 \\
\hline 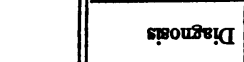 & s. & क & 8 & 容而 & 客西 & 容而 & 遅曋 & 客䡒 \\
\hline $\mathbf{r a g}$ & $\Sigma$ & sis & $\Sigma$ & $\Sigma$ & $\Sigma$ & $\Sigma$ & $\Sigma$ & $\Sigma$ \\
\hline $28 \mathrm{~V}$ & $\stackrel{\infty}{2}$ & 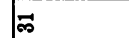 & 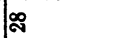 & 2 & $\infty$ & $\infty$ & \& & เุ \\
\hline ours $\mathrm{N}$ & $\infty$ & $\sum_{\mu \dot{1}}$ & هُ & مi & is & $\ddot{a}$ & 造 & 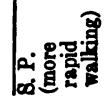 \\
\hline
\end{tabular}


enlarged. The heart was not enlarged on percussion. No accentuations or murmurs were found. The blood pressure was systolic 122, diastolic 84 . There was evidence of hypoplasia of the internal genitalia. X-ray examination showed a high diaphragm with transversely placed heart of normal size. There were no abnormalities about the sella turcica. The blood picture and sedimentation rate were normal. The glucose tolerance test was normal. The basal metabolism was within normal limits. Electrocardiogram showed only a left axis deviation of the type associated with transverse displacement of the heart (16).

\section{Vital capacities}

The vital capacities in the cases of obesity were distinctly below normal. Using West's (17) formula, we found that the average vital capacity in the three cases of obesity was 25 per cent below normal when calculated according to height standards, and 52 per cent below normal when the surface area standards were used. When the corrections which Pratt (18) gives for the values of West were made, the percentage below normal according to surface area standards was not quite so great.

In the normal cases these respective values were 9 per cent and 2 per cent. The averages are used here and will be used throughout this report for the purpose of comparing the 2 groups when they fairly represent what occurs in the individual cases.

\section{Respiratory minute volume}

The respiratory minute volumes at rest showed no significant differences in the two groups. During exercise, on the other hand, these respiratory minute volumes were increased to a greater extent in the obese persons. This increase was least marked in the obese patient E. W. whose response was comparable to that of the large normal person H. A. The average respiratory minute volume in the obese patients during exercise was 28.1 liters; in the normal people, 16.6 liters. This may be expected as a result of the difference in respiratory rates. If the "dead space" be taken as roundly equivalent to $200 \mathrm{cc}$., then a person who breathes 32 times a minute into the spirometer is expiring 6.4 liters of air which has not come in contact with the blood; while a person who breathes only 18 times a minute is expiring only 3.6 liters of unused air. The individual with the increased respiratory rate would require then for the same alveolar ventilation 2.8 liters of air more in a minute than the individual with the slower respiratory rate. The greater respiratory volumes in the obese cases may thus be associated with the differences in respiratory rates which were observed. At rest, the differences in respiratory rates were so small as to have no significant effect.

\section{Respiratory rates}

The respiratory rates showed distinct differences in the two groups. The respiratory rates in the sitting position in the obese patients were 11,16 , and 18 , with an average of 15 ; and in the normal cases the rates 
were $12,14,10$, and 12 , with an average of 12 . It is of interest to note that whereas in the normal cases the respiratory rates were unchanged in the sitting and standing positions or showed only occasional slight increase on standing, in the obese persons the respiratory rates usually showed a definite slight decrease in the standing position. This is most likely due to the diminution of the upward intra-abdominal pressure on the diaphragm in the standing position, thus allowing somewhat more freedom for lung excursions. The average respiratory rate during exercise in the obese patients was 30 per minute, in the normal cases 17 . This difference cannot be attributed to the differences in work. In one normal person the work was increased (walking faster) to the point where his oxygen consumption approximated that of the obese patients. Even with this increase in work, the respiratory rate was only 18 per minute.

\section{Oxygen consumption}

The oxygen consumption at rest was slightly greater in the cases of obesity than in the normal cases, but per square meter surface area it was approximately the same. During exercise, however, the oxygen consumption was distinctly greater in the cases of obesity.

Considering simply the oxygen consumptions at rest and during exercise, we find that whereas the average oxygen consumption per square meter surface area at rest in the cases of obesity was 1.48 liter and in the normal case 1.31 liter (difference of 12.68 per cent), it was 7.07 liters in the obese cases in exercise and only 4.42 liters in the normal cases (difference of 60 per cent). When the percentage increase in oxygen consumption in exercise over the resting state is calculated in the two groups, we find that the obese people showed an oxygen percentage increase in exercise of 490 per cent, the normals of 340 per cent, a difference of 150 per cent; calculated according to square meter surface area the increase in the obese cases was 480 per cent, in the normal cases 340 per cent, a difference of 140 per cent.

This greater oxygen consumption is more than can be accounted for simply by the greater work associated with the extra weight or the higher respiratory rates. The average weight of the obese cases was 27 per cent more than the normals; the average total oxygen consumption during exercise 66 per cent greater; and when calculated according to surface area, 60 per cent greater. It is practically impossible to estimate just how much more oxygen was required for the greater number of respiratory movements in the obese patients (19) but it is hardly likely that this was considerable, since the breathing was relatively shallow and not forced. In comparing the normal case with the case of obesity of the same weight and approximately the same age, we find the normal case with an oxygen consumption in exercise of 4.5 liters per square meter surface area, the obese case 6.1 liters, a difference of 33 per cent. While the difference in 
sex may account for some of this difference, its chief cause must undoubtedly be attributed to obesity.

Hill, Long and Lupton (8) define the oxygen requirement of any given exercise as the total oxygen used during the exercise and in complete recovery from it, in excess of the resting level. In the obese cases this oxygen requirement was distinctly greater than in the normal individuals, averaging 6.37 liters in the obese, and 3.05 liters in the normals. In the obese and normal cases of the same weight the values were 4.81 liters and 3.06 liters respectively.

The oxygen debt in the sense in which Hill, Long and Lupton (8) use the word is determined by measuring the total oxygen used in the recovery period, starting from the end of exercise, and subtracting the oxygen which would have been used in the same period had the body remained throughout at rest. It is assumed that the recovery period in question is sufficiently long to allow a complete return to the resting condition. This represents simply the extent to which the oxygen intake fails to meet the oxygen requirement during exercise, the body thus going into "debt." The oxygen debt may then be taken simply as the difference between oxygen intake and requirement. The oxygen debts in the obese cases were definitely higher than in the normal persons. The average value in the obese was 0.73 liter, in the normal cases 0.48 liter. In the obese and normal cases of the same weight the values were 0.80 liter and 0.35 liter respectively.

\section{Respiratory quotients}

Considerable caution must be exercised in evaluating the respiratory quotients in a study such as this because of their variability, with even slight irregularities in breathing. A particular attempt was made to control this factor. In recent years the numerous studies dealing with the metabolism of glucose and insulin have served to emphasize the many factors which must be considered in a study of the respiratory quotient (20). The changes which we observed, since they were more or less constant, may be mentioned. The respiratory quotients showed a slight tendency to rise during exercise in almost every case, with usually slightly greater rises in the obese individuals, associated with the greater exertion in the walking. Among others Hill, Long and Lupton (21) have shown that such slight increases in respiratory quotient take place during walking experiments.

\section{Arteriovenous difference and cardiac output}

In a study of cardiac output in exercise with the acetylene method, the question of applicability immediately arises. Baumann and Grollman (22) emphasized the fact that in cases in which the cardiac output is greater than 10 liters per minute, the method is not entirely satisfactory. The difficulty is due to the fact that in the minimum length of time 
necessary for a satisfactory mixture (alveolar sample) to be obtained by rebreathing in the lung-bag system, enough blood has returned to the right heart after a complete cycle to introduce an appreciable error in the arteriovenous difference when the heart output is greater than 10 liters per minute. In a study in which samples from the lung-bag system (mixture of acetylene, oxygen, and air) and from the arterial blood were taken simultaneously and analyzed for acetylene content, Grollman, Proger, and Dennig (23) found that even in rapid rebreathing following severe exercise, true alveolar samples were not obtained in less than 10 seconds in carrying out the acetylene procedure. In the present study the first sample in the exercise studies was taken at 12 seconds, so that satisfactory mixture was assured; the second sample was taken at 15-16 seconds. On the basis of the work of Baumann and Grollman (22), in which the right auricle in human beings was punctured in vivo, to learn among other things how much and how quickly acetylene returned to the right heart during rebreathing, we may assume that in the cases here recorded, in which during exercise the duration of rebreathing was 15-16 seconds, and in which the minute volumes varied between 10 and 12 liters, approximately 10 per cent acetylene returned to the right heart. This would indicate that the arteriovenous oxygen differences obtained are about 10 per cent too high. Assuming that there were no balancing factors, all the minute volumes in exercise may therefore be considered as approximately 10 per cent too low. (A-V difference is 10 per cent too high and M. V. $=\frac{\mathrm{O}_{2} \text { consumption }}{\mathrm{A}-\mathrm{V} \text { difference }}$ ) During rebreathing relatively less oxygen is taken up by the blood (quick increase in blood volume in the lungs before the oxygen consumption can be changed significantly) and this relatively smaller oxygen intake, in the blood returning to the right heart, increases the values for the cardiac output. This then serves as a balancing factor so that the error is in reality less than 10 per cent. As a matter of fact, in calculating minute volumes by the acetylene method and comparing them with minute volumes obtained by the Fick principle through direct cardiac punctures in man, Baumann and Grollman (22) found, in the one case in which the minute volume exceeded 10 liters (11.8 liters), that the two values corresponded almost exactly. They suggested that the two sources of error above mentioned probably balanced each other in this case. In any event, in the cases presented here, although the likelihood is that the error is considerably less than 10 per cent, we may assume a maximum possible error of 10 per cent in the cardiac output during exercise. Since this error was always in the same direction, the relative values remain unchanged. Should the errors have occurred only in the higher minute volumes (obese patients) the conclusions that are drawn below would not be altered, evidenced by the fact that an error could only lower the minute volume. 
The arteriovenous oxygen differences at rest in the obese cases were slightly higher than in the normal ones, the average being $85 \mathrm{cc}$. oxygen per $1000 \mathrm{cc}$. blood in the obese as compared with $74 \mathrm{cc}$. in the normal persons. Comparing the arteriovenous oxygen differences at rest and during exercise in the three normal individuals (excluding the large normal person) and in the three obese cases, we find that the arteriovenous oxygen differences increased relatively more in the obese cases; in the obese cases, the average of $85 \mathrm{cc}$. increased to $107 \mathrm{cc}$., and in the normal ones from $74 \mathrm{cc}$. to $84 \mathrm{cc}$. This might at first glance be taken to indicate a less efficient cardiac response on the part of the obese people. As shown by Dennig and Proger (24), and Bansi and Groscurth (25) cases with cardiac decompensation differ from normal cases in their response to exercise by showing a relatively greater increase in the arteriovenous oxygen difference. Since the consumption of oxygen during exercise in the obese people was, however, so much greater, and since the work performed by them was unquestionably more than that performed by the normal individuals, conclusions can not justifiably be drawn simply from a comparison of the responses of the arteriovenous oxygen differences. When the exercise was increased in the case of one of the normal men to the extent that his oxygen consumption during exercise increased approximately as much over the resting level as in the obese cases, it was found that the response in the arteriovenous oxygen difference corresponded to that seen in the obese cases. In this case the arteriovenous oxygen difference increased from $65 \mathrm{cc}$. to $90 \mathrm{cc}$. In the normal large person who, in carrying out the exercise, performed approximately the same work as the obese people, the response in the arteriovenous oxygen difference during exercise was as in the obese cases, going from $75 \mathrm{cc}$. per liter of blood at rest to $101 \mathrm{cc}$. during exercise. We find then that the arteriovenous oxygen differences in exercise in the obese people are essentially normal.

It was thought wise to regard measurements of minute volumes in the standing position as basal values in this study chiefly because satisfactory mixing in the lung-bag system is much more difficult to obtain in the obese cases in the sitting position. The work of Grollman (26) indicates that the minute volume does not differ essentially in the two positions.

The average value for the minute volume in the normal cases in the standing resting position was 3.7 liters. In the obese cases it was the same, 3.7 liters. The minute volumes per square meter surface area in the obese cases were slightly lower than in the normals (1.85 liter per square meter surface area in the obese and 1.93 liter in normals).

It follows from what has just been stated in regard to the arteriovenous oxygen differences that the minute volume in the obese people also showed a normal response to exercise $\left(\mathrm{M} . \mathrm{V} .=\frac{\mathrm{O}_{2} \text { consumption }}{\mathrm{A}-\mathrm{V} \mathrm{O}_{2} \text { difference }}\right)$. Thus if the arteriovenous oxygen differences increase normally in relation 
to the oxygen consumptions, as was the case in the obese patients, the minute volumes must also increase normally. Since the arteriovenous oxygen difference in all cases increased perceptibly during exercise, the minute volumes did not rise as a simple linear function of the oxygen absorption. We find, in agreement with Grollman (27), that the cardiac output even in light exercise is not a simple linear function of the oxygen consumption. The output of the heart during exercise in the obese cases was therefore normal, or rather, responded as it did in the normal cases. At the end of 4 minutes the cardiac outputs had returned practically to resting levels in all cases.

\section{Pulse rate}

The standing resting pulse rate was found to be higher in the obese cases, being 98,84 , and 80 respectively, than in the normal cases, where they were $70,78,82$, and 74 . In exercise the rates increased in the obese cases to 132,108 , and 90 respectively; in the normals, to $84,90,108$, and 80. In this instance, a consideration of the average pulse rate in exercise is misleading because in only one of the three cases of obesity did the pulse rate increase markedly during exercise. In the other two cases the increase in pulse rate was similar to that in the normal cases.

\section{Stroke volume}

The average stroke volume of cardiac output was essentially the same in the two groups during rest (obese cases $43.2 \mathrm{cc}$., normals $46.9 \mathrm{cc}$.) and during exercise (obese cases $108 \mathrm{cc}$., normals $112 \mathrm{cc}$.). Even the obese case which showed such a marked increase in pulse rate during exercise had a stroke volume of $86 \mathrm{cc}$. while walking.

\section{Blood pressure}

The blood pressure changes in exercise were remarkably constant and similar in all cases studied, obese and normal alike. The systolic pressure was observed to increase slightly during exercise while the diastolic pressure remained practically fixed. This is in agreement with the findings of Bansi and Groscurth (25), and indicates a rather fine quantitative adjustment between increased cardiac output and widening of the peripheral vascular bed since the resistance against which the heart has to work in order to open the aortic valves remains constant during rest and mild exercise.

\section{Lactic acid and other blood changes}

Lichtwitz (28) many years ago found that the lactic acid content of the blood in cases of obesity reached a higher level after exercise than in normal cases. Kugelmann (29), in a study of obese people with no signs of circulatory abnormalities, likewise found higher lactic acid values in obese cases as compared with normal ones after light exercise. In the 
two obese cases in this study in which the lactic acid values were obtained before and immediately after exercise, the values almost doubled; whereas in the normal individuals they remained practically unchanged. Even in the case of the normal person whose work was increased to the point where his oxygen consumption corresponded approximately to that of the obese persons, and in the case of the large normal person whose weight approximated that of the obese individuals, the lactic acid values showed no significant changes in exercise.

The $\mathrm{CO}_{2}$ content, the $\mathrm{CO}_{2}$ tension $\left(\mathrm{pCO}_{2}\right)$, and the $\mathrm{pH}$ of the arterial blood were calculated in one of the obese cases and compared with the values in one of the normal persons studied. Since no changes were observed in either case it was considered of no particular advantage to make these determinations in every case. These results indicate the mildness of the exercise studied.

\section{DISCUSSION}

The chief differences between the normal and the obese groups, in which there were no demonstrable pathological changes in the circulatory system, were found in the vital capacities, and in the pulse rate, respiratory rate, lactic acid changes in the blood, oxygen consumption, and oxygen debt on exercise.

The differences which were observed in the vital capacities agree essentially with those which Bowen (30) found in a study of the vital capacity in obesity. Bowen reported that the vital capacity of obese and "overweight" people averages 20 per cent less than normal, when the surface area standard is used; and suggests that the tendency to dyspnea which is so commonly seen in obese people may be accounted for in part by a reduction of the vital capacity. In this regard may be mentioned our observation that the obese persons showed a slight decrease in respiratory rate when standing, obviously due to freer mobility; also that in the one case in which it was attempted, it was impossible in the sitting posture to obtain a true alveolar air sample in the lung-bag system in the same time as in the standing position. This also is undoubtedly due to the mechanical interference with respiration in the obese patient. The diminished vital capacity in obesity may easily be accounted for on the basis of this mechanical disturbance.

In regard to differences in pulse rate, it is well to keep in mind how variable the pulse rate may be, also how totally independent of any primary circulatory disturbance. The study of the response of the pulse rate to exercise is a very unsafe method of estimating cardiac efficiency. As Mackenzie (31) writes, "in perfectly healthy individuals an increased rate in response to effort, and the time which it takes for the rate to return to normal, vary with the individual, the reason evidently being that the excitability of the cells of the sino-auricular node is not a constant 
factor amongst normal individuals." It is known that in trained athletes, the pulse rates at rest and in exercise are slower than in untrained individuals (Bainbridge, Bock, and Dill (32)). While it is possible that these differences in pulse rates may in some way be associated with a condition of the heart which affects its responsiveness, it does not, however, seem justifiable to attribute the tachycardia which is seen in obese people to a weakness of the heart. It is possible that purely mechanical disturbances (high diaphragm, increased fat about the heart, etc.) may lead to more rapid and smaller cardiac contractions.

As already mentioned, the increased respiratory rate during exercise in the obese cases apparently was not due simply to the greater oxygen consumption, for when the oxygen consumption was increased by increasing the work in one of the normal cases to approximately the same level as in the obese casè, the respiratory rate showed no significant change. The dyspnea which the obese people developed during exercise (average respiratory rate during exercise in the obese cases 30 , in the normal cases 17) cannot have been due to circulatory insufficiency, for the cardiac output was found to be normal. There was, furthermore, no evidence of a pulmonary affection which could have been responsible. It is also hardly likely that the slight increase in lactic acid in the blood in the obese cases could have brought about this increase in respiratory rate. Previous experiments on a normal subject (S. H. P.) in which lactic acid increases occurred of the same magnitude as those reported here in the cases of obesity, showed no such relationship between slight increases in the lactic acid of blood, and respiratory rates. As a matter of fact, in an experiment performed on this subject in which, after severe exercise, lactic acid in the blood increased from $8 \mathrm{mgm}$. to $104 \mathrm{mgm}$. per $100 \mathrm{cc}$., the respiratory rate rose only to 36 per minute, which is just slightly more than the rate observed in the cases of obesity during mild exercise. Experiments in which evidence was presented to support the theory that dyspnea was due to chemical changes within the brain $(33,34)$, such as increased production of lactic acid, are based on conditions of asphyxia or marked hypo-oxygenation of the arterial blood-conditions which did not obtain in the cases presented in this study. It is safe to exclude the chemical changes in the blood as a significant factor in the production of dyspnea. Bansi, Groscurth, and Weigel (35), attribute dyspnea in obesity to some inherent inability to excrete $\mathrm{CO}_{2}$. There results a piling up of $\mathrm{CO}_{2}$, which acts as a respiratory stimulant and is responsible for the increased respiratory rate. If this were true, we should expect to find relatively lower respiratory quotients in the cases of obesity during various stages of exercise. This we did not observe.

An analysis of the respiratory rates and respiratory minute volumes during exercise reveals the fact that the tidal flow is approximately the same in the two groups studied; that, although the rates vary so greatly 
there is approximately one liter expired with each breath in both groups of cases. It would appear then that although obese individuals breathe more rapidly than do normal people, they breathe just as deeply. It must be realized, however, that with an increase in respiratory rate, there is normally an increase in the depth of breathing so that a person who breathes 30 times a minute would normally be expected to have a greater tidal flow than a person who breathes only 17 times a minute. Thus when one of the subjects (S. H. P.) increased his exercise to such an extent that he was breathing 28 times a minute, his respiratory minute volume was 53 liters, and his tidal volume about 2 liters or about twice as great as it was when the exercise was such that he breathed only 18 times a minute as in the present study. The obese persons may, therefore, be considered to have distinctly low tidal volumes. Despite indications to the contrary, their breathing is definitely shallow, a fact which must be associated with the lowered vital capacities.

Since rapid, shallow breathing in the obese cases cannot be explained on the basis of primary disturbances in the circulation, lungs, or constituents in the blood, we are left with the assumption that it must be due to mechanical interference with respiration as a result of obesity. It is apparently easier for the obese person to take shallow breaths and more of them than to force the abdominal contents downward to any great extent with each inspiration.

The greater values of lactic acid in the blood in the obese cases during exercise are of interest because, in the absence of liver damage, they suggest circulatory insufficiency. Dresel and Himmelweit (36) found, as did Meakins and Long (37) earlier, that patients with cardiac insufficiency have definitely more lactic acid in the blood after exercise and that the lactic acid values return much more slowly to resting values than in normal people. Theoretically the muscle in cases of cardiac insufficiency is not able sufficiently to resynthesize or oxidize lactic acid resulting from the anoxybiotic breakdown of glycogen. Dresel and Himmelweit think that their method avoids the influence of the liver as a disturbing factor in their results, and also avoids the complication of training as a factor. Eppinger, Kisch, and Schwarz (5), and Meakins and Long (37) also found that after exercise the lactic acid values returned much more slowly to normal in cases of cardiac insufficiency than in cases with no damage of the heart. While one can no longer assume such direct and simple relationships between lactic acid metabolism and cardiac insufficiency as Eppinger, Kisch and Schwarz (5) do in their monograph, still it is true that the comparatively high values of lactic acid which we found in obese cases after exercise indicate definite chemical disturbances in the muscle, which may presumably be associated with cardiac insufficiency.

B. Kugelmann (29) used the technique described by Dresel and Himmelweit in a study of obese persons who, except for obesity, were 
in every respect normal. They obtained values for lactic acid which corresponded to the values found by Dresel and Himmelweit in cases with cardiac insufficiency. These increased lactic acid values Kugelmann also found in normal people who for two days before the experiment had been on a carbohydrate-free and protein-poor diet-in other words, in whom the glycogen deposits in the body had been materially diminished. Kugelmann presents evidence to show that there is relative insufficiency in the glycogen depots in obese people. He assumes that in obesity the diminution in the carbohydrate depots of the body are responsible for the disturbances in muscle, particularly in lactic acid metabolism. Since lactic acid metabolism is so intimately bound up with the supply of glycogen, his assumptions seem well founded. The high lactic acid values which we obtained, therefore, may be considered as due to disturbed intermediary metabolism with no relationship to circulatory insufficiency.

While it is no longer maintained that an exact simple relationship exists between oxygen debt and the amount of lactic acid present in the blood as first suggested by Hill, Long and Lupton (8), yet it is true that higher values of lactic acid in the blood at the end of short light work predicate higher oxygen debts, for more oxygen is required for resynthesis and oxygenation. The relatively greater oxygen debts which we observed in the cases of obesity are regarded as being due to the greater accumulation of lactic acid in the blood. Since the evidence indicates that excess lactic acid was not due to circulatory insufficiency, it follows that this greater oxygen debt was likewise not associated with any failure of the circulation.

We find then that the differences observed in the two groups studied may all be attributed to chemical and mechanical factors and that there is no evidence of a direct circulatory disturbance or inefficiency. The actual response of the heart to exercise in maintaining an adequate blood volume was normal. The greater increases in arteriovenous oxygen differences in exercise which have been observed in cases of definite cardiac insufficiency were not seen in the cases of obesity presented in this study. It appears then that the signs which may be associated with cardiac insufficiency observed in those cases of obesity which show no organic changes in the circulatory system are not due to an abnormal cardiac insufficiency. Although these cases had clinical signs which might be looked upon as due to inadequate cardiac response (dyspnea, diminished vital capacity, increased oxygen debt), they showed no evidence of abnormal cardiac insufficiency. It is to be remembered that there was no evidence of organic change in the circulatory system, no arteriosclerosis, no hypertension, no cardiac hypertrophy. These are patients then whom we might expect to find, with a return to normal weight, entirely normal individuals. 


\section{SUMMARY AND CONCLUSIONS}

1. Various phases of the circulation were studied in a group of obese patients who had no demonstrable pathological changes in the circulatory system, chiefly in their response to mild exercise in the form of walking on a treadmill. The results were compared with the results in a group of normal people.

2. The responses of the cardiac output and arteriovenous oxygen differences to exercise were similar in the two groups.

3. The chief differences between the two groups were found in the vital capacities, and in the pulse rates, respiratory rates, blood lactic acid changes, oxygen consumptions, and oxygen debts in exercise.

4. On the basis of the findings presented, it is believed that the symptoms which are so commonly associated with cardiac insufficiency and which are frequently observed in cases of simple obesity are not due to an inefficient circulatory response, but rather to mechanical and chemical disturbances associated with obesity.

\section{BIBLIOGRAPHY}

1. Laennec, R. T. H., Traité de l'auscultation médiate et des maladies des poumons et du coeur. Part III. Paris, 1831, 3rd ed., p. 166.

2. Stokes, W., The Diseases of the Heart and Aorta. Lindsay and Blakiston, Philadelphia, 1854, p. 302.

3. Hirsch, C., Deutsches Arch. f. klin. Med., 1899, lxiv, 597. Über die Beziehungen zwischen dem Herzmuskel und der Körpermuskulatur und über sein Verhalten bei Herzhypertrophie.

4. Romberg, E., Die Krankheiten des Herzens und der Blutgefässe. Stuttgart, 1921, 3rd ed., p. 202.

5. Eppinger, H., Kisch, F., and Schwarz, H., Das Versagen des Kreislaufes. Julius Springer, Berlin, 1927.

6. Groscurth, G., Ztschr. f. klin. Med., 1929, cxi, 357. Die Kreislaufgeschwindigkeit bei der Fettsucht.

7. Fletcher, W. M., J. Physiol., 1902, xxviii, 474. The Relation of Oxygen to the Survival Metabolism of Muscle.

8. Hill, A. V., Long, C. N. H., and Lupton, H., Proc. Roy. Soc. Lond., B, 1924, xcvi, 438. Muscular Exercise, Lactic Acid, and the Supply and Utilisation of Oxygen. Parts I and II.

9. Marshall, E. K., Jr., and Grollman, A., Am. J. Physiol., 1928, lxxxvi, 117. A Method for the Determination of the Circulatory Minute Volume in Man.

10. Grollman, A., Am. J. Physiol., 1929, lxxxviii, 432. The Determination of the Cardiac Output of Man by the Use of Acetylene.

11. Van Slyke, D. D., and Stadie, W. C., J. Biol. Chem., 1921, xlix, 1. The Determination of the Gases of the Blood.

12. Hastings, A. B., and Sendroy, J., Jr., J. Biol. Chem., 1924, 1xi, 695. Studies of Acidosis. XX. The Colorimetric Determination of Blood $\mathrm{pH}$ at Body Temperature without Buffer Standards.

13. Austin, J. H., Cullen, G. E., Hastings, A. B., McLean, F. C., Peters, J. P., and Van Slyke, D. D., J. Biol. Chem., 1922, liv, 121. Studies of Gas and Electrolyte Equilibria in Blood. I. Technique for Collection and 
Analysis of Blood, for its Saturation with Gas Mixtures of Known Composition.

14. Hirsch-Kaufmann, H., Ztschr. f. physiol. Chemie, 1924, cxl, 25. Zur Methodik der Milchsäurebestimmung in tierischen Organen.

15. Lehnartz, E., Ztschr. f. physiol. Chemie, 1928, clxxix, 1. Zur Methodik der Bestimmung kleinster Milchsäuremengen.

16. Proger, S. H., Arch. Int. Med., 1931, xlvii, 64. The Electrocardiogram in Obesity.

17. West, H. F., Arch. Int. Med., 1920, xxv, 306. Clinical Studies on the Respiration. VI. A Comparison of Various Standards for the Normal Vital Capacity of the Lungs.

18. Pratt, J. H., Am. J. Med. Sci., 1922, clxiv, 819. Long-continued Observations on the Vital Capacity in Health and Heart Disease.

19. Hill, A. V., Long, C. N. H., and Lupton, H., Proc. Roy. Soc. London, B, 1925, xcvii, 128. Muscular Exercise, Lactic Acid, and the Supply and Utilisation of Oxygen. Part VI.

20. Geelmuyden, H. C., Ergebn. d. Physiol., 1931, xxxi, 1. Über einige Fragen und Aufgaben der Diabetesforschung nebst Richtlinien einer Stoffwechsel-physiologischen Theorie des Diabetes mellitus.

21. Hill, A. V., Long, C. N. H., and Lupton, H., Proc. Roy. Soc. London, B, 1925, xcvii, 84. Muscular Exercise, Lactic Acid, and the Supply and Utilisation of Oxygen. Part IV.

22. Baumann, H., and Grollman, A., Ztschr. f. klin. Med., 1930, cxv, 41. Über die theoretischen und praktischen Grundlagen und die klinische Zuverlässigkeit der Acetylenmethode zur Bestimmung des Minutenvolumens.

23. Grollman, A., Proger, S. H., and Dennig, H., Arch. f. exp. Path. u. Pharm., 1931, clxii, 463. Zur Bestimmung des Minutenvolumens mit der Azetylenmethode bei Arbeit, bei normalen und kranken Menschen.

24. Dennig, H., and Proger, S. H., Kong. f. Inn. Med. Wiesbaden, 1931.

25. Bansi, H. W., and Groscurth, G., Klin. Wchnschr., 1930, ix, 1902. Funktionsprüfung des Kreislaufs durch Messung der Herzarbeit.

26. Grollman, A., Am. J. Physiol., 1928, lxxxvi, 285. The Effect of Variation in Posture on the Output of the Human Heart.

27. Grollman, A., Am. J. Physiol., 1931, xcvi, 8. Physiological Variations in the Cardiac Output of Man. XIII. The Effect of Mild Muscular Exercise on the Cardiac Output.

28. Lichtwitz, L., Quoted by Kugelmann, ref. 29, below.

29. Kugelmann, B., Ztschr. f. klin. Med., 1931, cxv, 454. Untersuchungen zur Fettsucht als ein Problem intermediärer Stoffewechselstörung.

30. Bowen, B. D., Arch. Int. Med., 1923, xxxi, 579. The Relation of Age and Obesity to Vital Capacity.

31. Mackenzie, J., Diseases of the Heart. Oxford Med. Publications, 1925, 4th ed., p. 112.

32. Bainbridge, F. A., Bock, A. V., and Dill, D. B., The Physiology of Muscular Exercise. Longmans, Green and Co., London, New York, Toronto, 1931.

33. Winterstein, H., Klin. Wchnschr., 1928, vii, 241. Die Reaktionstheorie der Atmungsregulation im Lichte neuerer Untersuchungen.

34. McGinty, D. A., and Gesell, R., Am. J. Physiol., 1925, 1xxv, 70. On the Chemical Regulation of Respiration. II. A Quantitative Study of the Accumulation of Lactic Acid in the Isolated Brain during Anaerobic 
Conditions and the Role of Lactic Acid as a Continuous Regulator of Respiration.

35. Bansi, H. W., Groscurth, G., and Weigel, H., Klin. Wchnschr., 1929, viii, 1409. Zur Frage der Kurzatmigkeit bei Fettsüchtigen und Asthenikern.

36. Dresel, K., and Himmelweit, F., Klin. Wchnschr., 1929, viii, 294. Kreislaufinsuffizienz und Muskelstoff wechsel.

37. Meakins, J., and Long, C. N. H., J. Clin. Invest., 1927, iv, 273. Oxygen Consumption, Oxygen Debt, and Lactic Acid in Circulatory Failure.

38. Rappaport, I., J. Am. Med. Assoc., 1929, xcii, 1158. Blood Pressure and Respiration. Hyperventilation as a Treatment for Hypertension.

39. Lintz, W., Internat. Clin., 1927, iv, 176. Consideration of High Blood Pressure; Small Lungs.

40. Weinstein, S., Med. Klin., 1928, xxiv, 418. Röntgensymptome bei hohem Blutdruck. 